Originalien

Anaesthesist 2021 · 70:298-307

https://doi.org/10.1007/s00101-020-00877-5

Received: 25 May 2020

Revised: 22 September 2020

Accepted: 23 September 2020

Published online: 10 November 2020

(c) The Author(s) 2020, korrigierte Publikation

2021

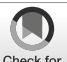

\section{Electronic supplementary} material

The online version of this article (https://doi. org/10.1007/s00101-020-00877-5) contains one further table and two figures. The article and additional material are available at www. springermedizin.de. Please enter the title of the article in the search field. You will find the additional material under "Ergänzende Inhalte" in the article.

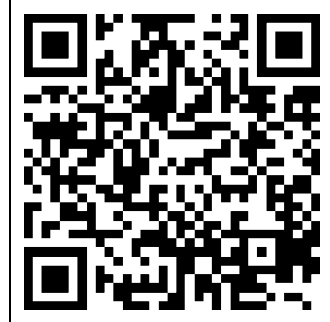

L. Eberhart ${ }^{1}$ - G. Geldner ${ }^{2}$ A. Kowark ${ }^{3}$ - T.-P. Zucker ${ }^{4}$ S. Kreuer ${ }^{5} \cdot$ M. Przemeck ${ }^{6}$.

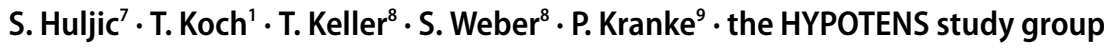
' Department of Anesthesiology \& Intensive Care, Philipps University Marburg, Marburg, Germany ${ }^{2}$ Clinic for Intensive Care, Emergency Medicine and Pain Therapy, Hospital Ludwigsburg, Ludwigsburg, Germany

${ }^{3}$ Department of Anesthesiology, Medical Faculty, RWTH Aachen University, Aachen, Germany

${ }^{4}$ Department of Anesthesiology, Intensive Care and Pain Therapy, Academic Teaching Hospital Traunstein, Traunstein, Germany

${ }^{5}$ Department of Anesthesiology, Intensive Care and Pain Therapy, University Hospital Saarland, Homburg, Germany

${ }^{6}$ Department of Anesthesiology and Intensive Care, DIAKOVERE Annastift, Hannover, Germany

${ }^{7}$ ratiopharm GmbH, Ulm, Germany

${ }^{8}$ ACOMED Statistik, Leipzig, Germany

${ }^{9}$ Department of Anesthesia and Critical Care, University Hospital Würzburg, Würzburg, Germany

\title{
Treatment of intraoperative hypotension with cafedrine/theodrenaline versus ephedrine
}

\section{A prospective, national, multicenter, non- interventional study - the HYPOTENS trial}

\section{Brief introduction to the topic}

Sympathomimetic drugs play an essential role in the treatment of hypotensive states $[1,2]$. A number of pharmacotherapies are currently available, including phenylephrine, norepinephrine, cafedrine/theodrenaline $(\mathrm{C} / \mathrm{T})$ and ephedrine (E). While $\mathrm{C} / \mathrm{T}$ has been widely used in Germany since 1963 [3, 4]. E is more commonly used internationally and was approved for use in Germany only in 2013 [5]. Both agents stimulate alpha- and beta-adrenoceptors, making them particularly suited for the treatment of hypotension caused by both cardiac depression and vasodilatation $[1$, 6].

\section{Background}

Intraoperative hypotension (IOH) is a common side effect of anesthesia and is associated with perioperative morbidity and mortality $[7,8]$, making rapid and precise recovery of blood pressure crucial. Restoring and maintaining optimal blood pressure has been shown to reduce organ damage [9]. So far, comparative clinical studies that investigated the combination of $\mathrm{C} / \mathrm{T}$ and $\mathrm{E}$ for the treatment of hypotension are lacking and the optimal drug for the pharmacological treatment of $\mathrm{IOH}$ remains a subject of long-standing debate $[10,11]$.

All members of the HYPOTENS study group are listed in alphabetical order at the end of this article.

\section{Data sharing}

Qualified researchers may request access to patient-level data and related study documents, including the study protocol and the statistical analysis plan. Requests will be reviewed for scientific merit, product approval status, and conflicts of interest. Patient-level data will be deidentified and study documents will be redacted to protect the privacy of trial participants and to protect commercially confidential information. Please email USMedInfo@tevapharm.com to make your request. 


\section{Treten Sie in den Austausch \\ Diese Arbeit einer deutschsprachigen Autorengruppe wurde für Der Anaesthesist in Englisch eingereicht und angenommen. Die deutsche Zusammenfassung wurde daher etwas ausführlicher gestaltet. Wenn Sie über diese Zusammenfassung hinaus Fragen haben und mehr wissen wollen, nehmen Sie gern in Deutsch über die Korrespondenzadresse am Ende des Beitrags Kontakt mit den Autoren auf. Die Autoren freuen sich auf den Austausch mit Ihnen.}

This article presents the first results from HYPOTENS, a prospective, national, multicenter, open-label, twoarmed, non-interventional study that was designed to compare the effectiveness (i.e. the clinical effects observed during standard medical practice) of $\mathrm{C} / \mathrm{T}$ with $\mathrm{E}$ for treatment of $\mathrm{IOH}$ [12]. We focused here on a prospectively defined cohort of patients (cohort A in [12]) with an increased risk of developing IOH, namely patients $\geq 50$ years old with comorbidities undergoing general anesthesia with propofol and high-dose fentanyl $\geq 0.2 \mathrm{mg}$ (or equivalent) [13]. This population includes older patients who have an increased risk of $\mathrm{IOH}$ associated mortality [14]. According to a survey conducted among clinicians to characterize features of an ideal antihypotensive drug [12], the primary objectives were established to examine rapidity of onset and the ability to attain individually defined arterial blood pressure values without relevant increases in heart rate. Secondary outcomes included examination of treatment satisfaction and the number of additional boluses or other accompanying measures required to achieve target blood pressure.

\section{Methods}

The leading ethics committee at the Philipps University of Marburg granted approval for the study on 15 April 2016 (Az. 14/16). Confirmation was then provided to each participating physician/site for approval by local ethics committees. The study was conducted in compliance with the Declaration of Helsinki. Informed consent was obtained from all patients, who agreed that their data could be used. The trial was registered at clinicaltrials.gov (NCT02893241) and the German Clinical Trials Registry (DRKS00010740).

Detailed information about the study design, recruitment, patient population and endpoints is provided in the HYPOTENS study design publication [12].

\section{Patient population}

Patients were recruited between July 2016 and February 2018 from 53 German hospitals with 66 surgical specialties and different levels of care. Patients $\geq 50$ years old with an American Society of Anesthesiologists (ASA) classification of 2-4 who received general anesthesia with propofol and fentanyl $\geq 0.2 \mathrm{mg}$ (or equivalent) were screened in this cohort.

\section{Definition of hypotension}

Patients were eligible for inclusion in this cohort if they required treatment for hypotension, defined as systolic blood pressure (SBP) $<100 \mathrm{~mm} \mathrm{Hg}$ and/or a drop of more than $20 \%$ compared with a preoperative baseline SBP measurement taken in resting conditions.

\section{Study medication}

A 20:1 combination of $\mathrm{C} / \mathrm{T}$ (cafedrine hydrochloride $200 \mathrm{mg} /$ theodrenaline hydrochloride $10 \mathrm{mg}$ per $2 \mathrm{ml}$ solution) was supplied by ratiopharm GmbH (Ulm, Germany) and E (ephedrine hydrochloride $10 \mathrm{mg}$ per $1 \mathrm{ml}$ solution) was obtained from Sintetica $\mathrm{GmbH}$ (Münster, Germany) [4, 5].

\section{Study design}

Surgical departments routinely using either $\mathrm{C} / \mathrm{T}$ or $\mathrm{E}$ were randomly selected from all registered departments through a predefined, standardized algorithm. A computer-aided matching process was used to pair the selected departments with the same surgical specialties according to prespecified criteria (for more details, please refer to the study design publication [12]).
Since the participating departments generally used either $\mathrm{C} / \mathrm{T}$ or $\mathrm{E}$ according to local standard operating procedures, patients were recruited to a treatment arm according to the drug routinely applied by that surgical specialty, thus the design and analysis refer to clusters defined by specialist department within the clinic [12]. According to the non-interventional design of the study, the final decision to treat hypotension and thus to include a patient in the study was left to the attending anesthetist. Once a patient was deemed eligible, each physician was required to assign a minimum target SBP $\left(\mathrm{SBP}_{\min }\right)$ prior to initial treatment. To discriminate from prophylactic use, treatment was defined as an SBP increase $>5 \mathrm{~mm} \mathrm{Hg}$. There were no specific dose requirements for either medication. Any additional treatment for blood pressure was recorded. The observational period was $15 \mathrm{~min}$ after initial treatment.

\section{Trial endpoints}

The superiority of either study medication was confirmed if at least one of the two following primary endpoints were demonstrated: 1) smaller area under the curve (AUC) between the recorded SBP and the $\mathrm{SBP}_{\text {min }}$ as defined by the attending anesthetist. For a detailed description, please refer to the study design publication [12], 2) lower incidence of newly occurring heart rate $\geq 100$ beats/min. Multiple testing was taken into account by adjusting the alpha level (0.025).

Post-hoc analyses examined the change in SBP and heart rate from baseline after initial study treatment application. Secondary endpoints included the number of additional boluses or other accompanying measures required for hemodynamic stabilization (e.g. volume adjustment, positioning changes, norepinephrine and other drugs). Physicians were also required to assess rapidity of onset and treatment precision on a Likert scale from 1 (very good) to 6 (very poor).

\section{Statistical analysis}

Continuously scaled data are presented as mean, standard deviation, median, 
Anaesthesist 2021 · 70:298-307 https://doi.org/10.1007/s00101-020-00877-5

(c) The Author(s) 2020

\author{
L. Eberhart · G. Geldner · A. Kowark · T.-P. Zucker · S. Kreuer · M. Przemeck · S. Huljic · T. Koch • T. Keller · S. Weber · P. Kranke · the HYPOTENS study \\ group
}

Treatment of intraoperative hypotension with cafedrine/theodrenaline versus ephedrine. A
prospective, national, multicenter, non-interventional study-the HYPOTENS trial

Abstract

Background. Sympathomimetic drugs are a therapeutic cornerstone for the management of hypotensive states like intraoperative hypotension $(\mathrm{IOH})$. While cafedrine/theodrenaline $(C / T)$ is widely used in Germany to restore blood pressure in patients with $\mathrm{IOH}$, more research is required to compare its effectiveness with alternatives such as ephedrine (E) that are more commonly available internationally.

Methods. HYPOTENS (NCT02893241, DRKS00010740) was a prospective, national, multicenter, open-label, two-armed, noninterventional study that compared $\mathrm{C} / \mathrm{T}$ with $\mathrm{E}$ for treatment of $\mathrm{IOH}$. We describe a prospectively defined cohort of patients $\geq 50$ years old with comorbidities undergoing general anesthesia induced with propofol and fentanyl. Primary objectives were to examine treatment precision, rapidity of onset and the ability to restore blood pressure without relevant increases in heart rate. Secondary endpoints were treatment satisfaction and the number of required additional boluses or other accompanying measures.

Results. A total of 1496 patients were included in the per protocol analysis. Overall, effective stabilization of blood pressure was achieved with both $\mathrm{C} / \mathrm{T}$ and $\mathrm{E}$. Post-hoc analysis showed that blood pressure increase from baseline was more pronounced with $\mathrm{C} / \mathrm{T}$. Fewer additional boluses or other accompanying measures were required in the $\mathrm{C} / \mathrm{T}$ arm. The incidence of tachycardia was comparable between groups. Post-hoc analysis showed that E produced dose-dependent elevated heart rate values. By contrast, heart rate remained stable in patients treated with $\mathrm{C} / \mathrm{T}$. Physicians reported a higher level of treatment satisfaction with $C / T$, with a higher proportion of anesthetists rating treatment precision and rapidity of onset as good or very good when compared with $\mathrm{E}$.

Conclusion. Neither drug was superior in restoring blood pressure levels; however, post-hoc analyses suggested that treatment is more goal-orientated and easier to control with $\mathrm{C} / \mathrm{T}$. Heart rate was shown to be more stable with $\mathrm{C} / \mathrm{T}$ and fewer additional interventions were required to restore blood pressure, which could have contributed to the increased treatment satisfaction reported by anesthetists using $\mathrm{C} / \mathrm{T}$.

\section{Keywords}

Hypotension - Cafedrine, theodrenaline drug combination - Ephedrine - Catecholamines · Sympathomimetics · Akrinor . Haemodynamics - Vasopressor

\title{
Therapie der intraoperativen Hypotonie mit Cafedrin/Theodrenalin vs. Ephedrin. Ergebnisse der HYPOTENS-Studie, einer prospektiven, nationalen, multizentrischen, nicht-interventionellen Untersuchung bei Patienten, die eine Vollnarkose erhalten
}

Zusammenfassung

Hintergrund. Die medikamentöse Therapie mit Sympathomimetika bildet einen Grundpfeiler der Behandlung relevanter Blutdruckabfälle, so auch der intraoperativen Hypotonie ( $\mathrm{IOH})$. Dieses häufige Problem ist mit Endorganschäden assoziiert, wobei Nierenversagen und eine erhöhte Rate kardiovaskulärer Komplikationen am besten dokumentiert sind. Die Datenlage verdeutlicht die Notwendigkeit, dass eine $\mathrm{IOH}$ schnell und konsequent therapiert werden muss. Obwohl Cafedrin/Theodrenalin (C/T) in Deutschland häufig in dieser Indikation eingesetzt wird, fehlte bislang ein Wirksamkeitsvergleich mit international verfügbaren Alternativen wie Ephedrin (E).

Methoden. HYPOTENS ist eine prospektive, nationale, multizentrische (53 Kliniken mit 66 operativen Abteilungen), offene, zweiarmige, nicht-interventionelle Studie zum Vergleich der Wirksamkeit von $\mathrm{C} / \mathrm{T}$ und $\mathrm{E}$ bei der $\mathrm{IOH}-T h e r a p i e$ unter klinischen Routinebedingungen. Diese Studie beschreibt eine prospektiv definierte Kohorte von Patienten im Alter von $\geq 50$ Jahren mit Komorbiditäten, deren Allgemeinanästhesie mit Propofol und Fentanyl ( $\geq 0,2 \mathrm{mg}$ oder Äquivalent) eingeleitet wurde. Alle Patienten hatten intraoperativ eine therapiepflichtige $\mathrm{IOH}$ entwickelt und wurden nach dem jeweiligen lokalen Standard mit $\mathrm{C} / \mathrm{T}$ oder $\mathrm{E}$ therapiert. Die primären Studienziele waren Präzision und Schnelligkeit des Blutdruckanstiegs auf einen vor der Behandlung individuell festgelegten MindestZielblutdruck, ohne dabei einen relevanten Anstieg der Herzfrequenz zu verursachen. Die Therapiezufriedenheit der Anästhesisten und die Anzahl zusätzlicher Bolusinjektionen oder weiterer kreislaufstabilisierender Maßnahmen waren sekundäre Endpunkte.

Ergebnisse. Insgesamt 1496 Patienten wurden protokollgemäß behandelt und ausgewertet. Eine Kreislaufstabilisierung wurde mit beiden Therapieoptionen erreicht. Post-hoc-Analysen zeigen, dass der Blutdruckanstieg unter $\mathrm{C} / \mathrm{T}$ ausgeprägter war und gleichzeitig weniger zusätzliche Boli der jeweiligen Substanz appliziert und zusätzliche kreislaufstabilisierende Interventionen durchgeführt werden mussten. Die Inzidenz von Tachykardien war in beiden Behandlungsgruppen vergleichbar. Unter E kam es jedoch zu einer dosisabhängigen Erhöhung der Herzfrequenz, während bei den mit C/T behandelten Patienten die Herzfrequenz stabil blieb. Die Therapiezufriedenheit der Anästhesisten war im C/T-Arm höher. Schlussfolgerung. Hinsichtlich der Kreislaufstabilisierung war keine der beiden Therapieoptionen überlegen. Post-hocAnalysen deuten darauf hin, dass C/T unter Routinebedingungen eine zielorientiertere und einfacher zu steuernde Kreislaufstabilisierung ermöglicht. Die seltener erforderlichen erweiterten Therapiemaßnahmen zur ergänzenden $\mathrm{IOH}$-Korrektur stellen einen möglichen Grund für die höhere Anwenderzufriedenheit dar.

\section{Schlüsselwörter}

Hypotonie · Cafedrin/TheodrenalinMedikamentenkombination - Ephedrin . Katecholamine Sympathomimetika · Akrinor . Hämodynamik · Vasopressor 


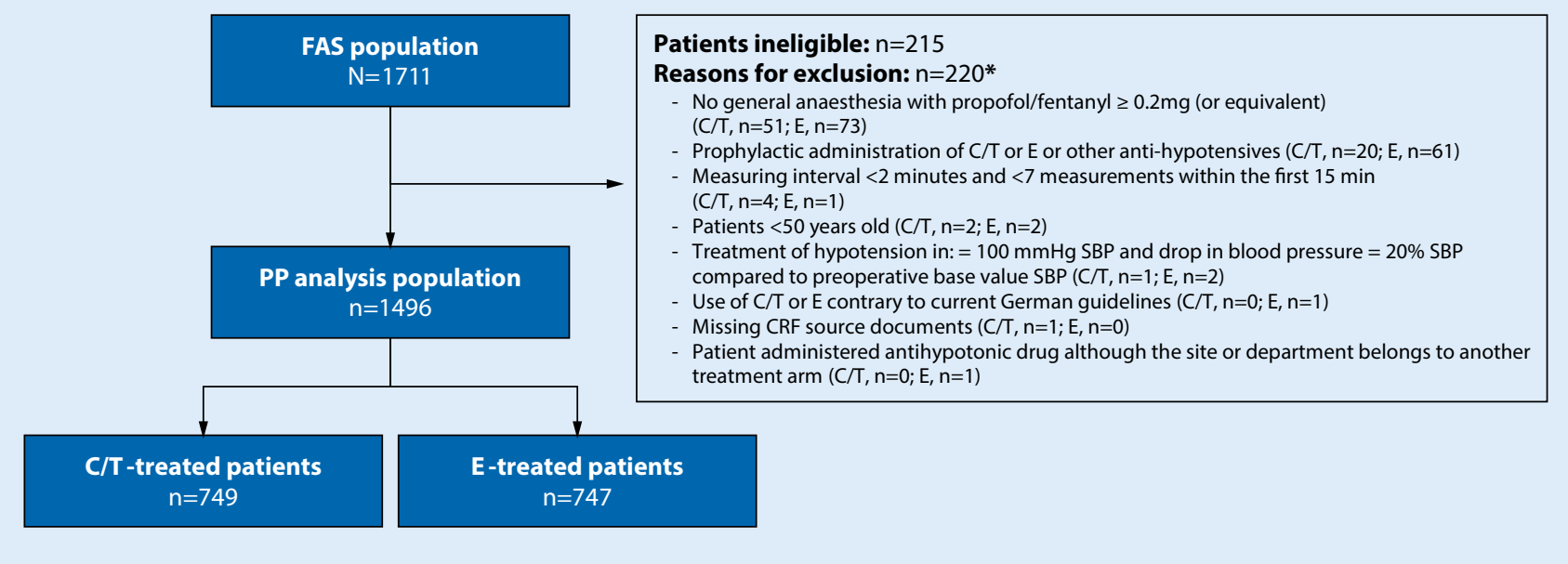

Fig. $1 \Delta$ Flow chart for a cohort of patients $\geq 50$ years old with pre-existing comorbidities who received general anesthesia as part of the HYPOTENS study. $C R F$ case report form, $C / T$ cafedrine/theodrenaline, $E$ ephedrine, $F A S$ full analysis set, $P P$ per-protocol, SBP systolic blood pressure. Asterisk Patients may be included in more than one exclusion category

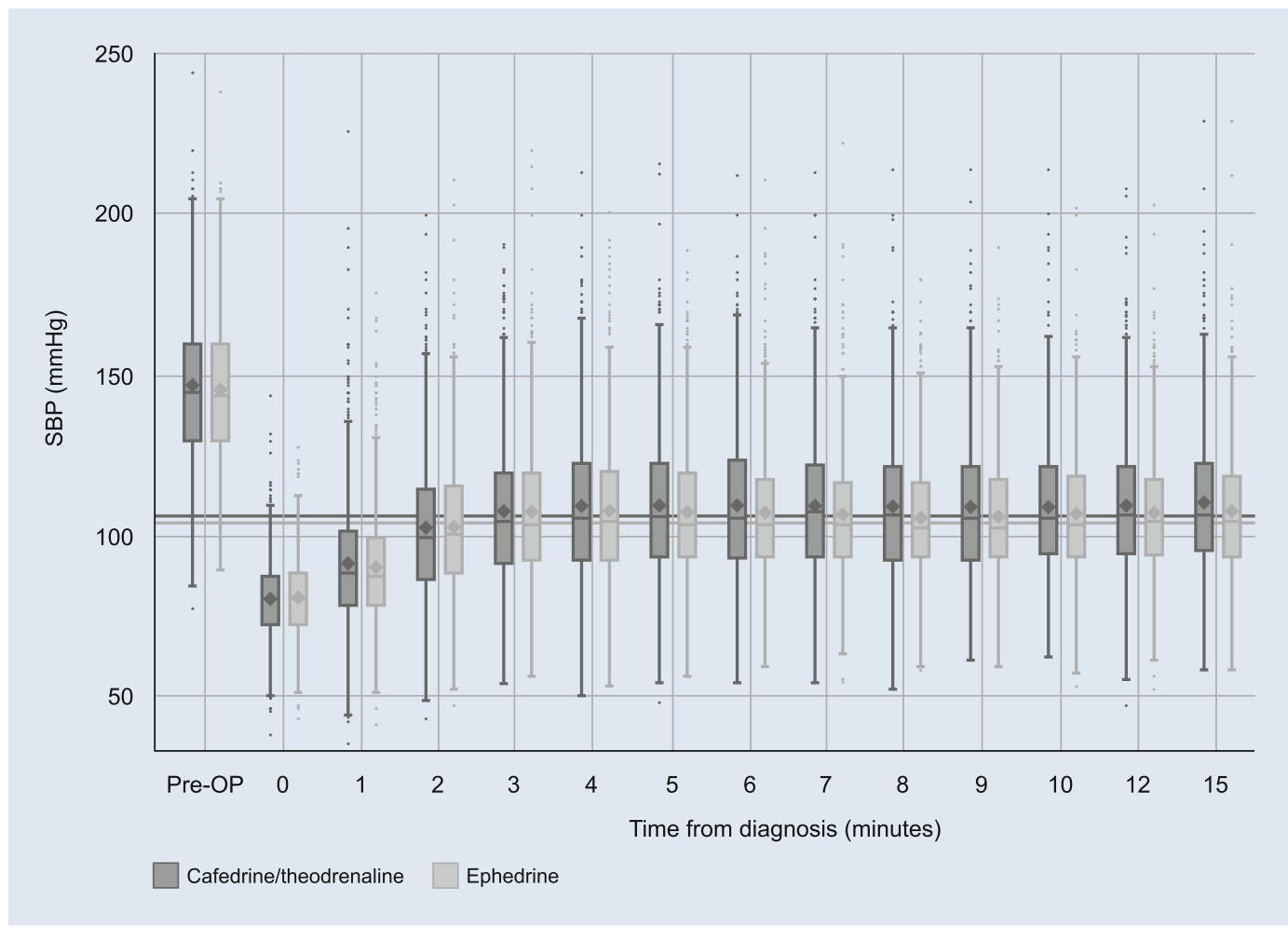

Fig. $2 \triangleleft$ SBP measured before the operation, at diagnosis of hypotension, and during the first 15 min after application of either $\mathrm{C} / \mathrm{T}$ or E. Shown are the mean (diamonds), median (dash), 25th/75th percentiles (box), $1.5 * \mathrm{IQR}$ (whiskers), and outliers (dots). Horizontal grey lines indicate the SBP target as defined by the treating physician. C/T cafedrine/ theodrenaline, Eephedrine, $I Q R$ interquartile range, $O P$ operation, SBP systolic blood pressure minimum and maximum. Categorically scaled data are shown as absolute and relative frequencies.

Efficacy endpoints were analyzed by applying a mixed model analysis, including fixed (treatment and type of surgical department) and random (matched departments) effects. For additional analyses of variables measured at different time points, the patient was also included as a random factor. Depending on depen- dent-variable scaling, results were analyzed based on the linear, logistic or Poisson regression framework. Where there were relevant deviations from a normal distribution in continuously scaled data, Box-Cox transformed values were analyzed. Efficacy endpoint analyses were prospectively defined in a statistical analysis plan that was finalized prior to closure of the study database. Sample size and power calculations were described pre- viously [12]. Analysis was performed by ACOMED Statistik (Leipzig, Germany) using SAS ${ }^{\circledR}$ software version 9.4 (SAS Institute Inc., Cary, NC, USA).

\section{Results}

\section{Patients}

A total of 1711 patients were included in the full analysis set (FAS) (• Fig. 1). 


\section{Table 1 Patient characteristics (per protocol analysis set}

\begin{tabular}{|c|c|c|}
\hline Parameter & $\begin{array}{l}C / T \\
(n=749)\end{array}$ & $\begin{array}{l}E \\
(n=747)\end{array}$ \\
\hline \multicolumn{3}{|l|}{ Demographic parameters } \\
\hline \multicolumn{3}{|l|}{ Sex, $n(\%)$} \\
\hline Female & $393(52.5)$ & $375(50.2)$ \\
\hline Male & $356(47.5)$ & $372(49.8)$ \\
\hline Age (years) & $70 \pm 10$ & $70 \pm 10$ \\
\hline Weight (kg) & $79 \pm 17$ & $81 \pm 18$ \\
\hline Height $(\mathrm{cm})$ & $170 \pm 9$ & $170 \pm 9$ \\
\hline \multicolumn{3}{|l|}{$A S A, n(\%)$} \\
\hline II & $426(56.9)$ & $451(60.4)$ \\
\hline III & $315(42.1)$ & $290(38.8)$ \\
\hline IV & $8(1.1)$ & $6(0.8)$ \\
\hline \multicolumn{3}{|l|}{ General anesthesia, initial medication } \\
\hline Initial dose of propofol (mg/kg) & $2.09 \pm 0.65$ & $2.06 \pm 0.57$ \\
\hline Initial dose of opioid equivalents $(\mu \mathrm{g} / \mathrm{kg})$ & $3.41 \pm 1.41$ & $3.34 \pm 1.26$ \\
\hline \multicolumn{3}{|c|}{ Patients with antihypertensive drugs not withdrawn prior to surgery, $\boldsymbol{n}(\%)$} \\
\hline Antihypertensive drugs & $375(50.1)$ & $404(54.1)$ \\
\hline Beta blocking agents & $220(29.4)$ & $274(36.7)$ \\
\hline Alpha and beta blocking agents & $18(2.4)$ & $8(1.1)$ \\
\hline Alpha blocking agents & $29(3.9)$ & $31(4.2)$ \\
\hline ACE-inhibitors/AT-2 antagonists/renin-inhibitors & $185(24.7)$ & $175(23.4)$ \\
\hline \multicolumn{3}{|l|}{ Comorbidities, $\boldsymbol{n}(\%)$} \\
\hline Circulatory system disease & $538(71.8)$ & $582(77.9)$ \\
\hline Hypertension & $497(66.4)$ & $545(73.0)$ \\
\hline Left ventricular heart failure & $73(9.7)$ & $81(10.8)$ \\
\hline Right ventricular heart failure & $2(0.3)$ & $5(0.7)$ \\
\hline \multicolumn{3}{|l|}{ Hemodynamic monitoring, $n$ (\%) } \\
\hline Non-invasive & $684(91.3)$ & $650(87.0)$ \\
\hline Invasive & $65(8.7)$ & $97(13.0)$ \\
\hline \multicolumn{3}{|l|}{ Hypotensive episodes, $\boldsymbol{n}$ (\%) } \\
\hline Before the start of surgery (cut), $n$ (\%) & $643(85.8)$ & $665(89.0)$ \\
\hline After the start of surgery (cut), $n$ (\%) & $87(11.6)$ & $70(9.4)$ \\
\hline $\begin{array}{l}\text { Median (Q1; Q3) time between anesthesia induction and } \\
\text { diagnosis of hypotension (minutes) }\end{array}$ & $\begin{array}{l}14.0 \\
(Q 1: 6 ; Q 3: 24)\end{array}$ & $\begin{array}{l}12.0 \\
(\mathrm{Q} 1: 6, \mathrm{Q} 3: 22)\end{array}$ \\
\hline Time until surgery (cut) (min) & $37.9 \pm 19.2$ & $35.2 \pm 16.5$ \\
\hline $\begin{array}{l}\text { Beginning of surgery (cut) during observation period (up to } \\
15 \text { min after application), } n(\%)\end{array}$ & $256(39.1)$ & 294 (43.6) \\
\hline
\end{tabular}

Of these patients 1496 were included in the per-protocol (PP) analysis set $(\mathrm{C} / \mathrm{T}$ : $n=749$; E: $n=747)$. Baseline characteristics of the study subjects are presented in - Table 1.

Hypotension that required treatment occurred at a median of $14 \mathrm{~min}$ (Q1: $6 \mathrm{~min}, \mathrm{Q} 3: 24 \mathrm{~min}, \mathrm{C} / \mathrm{T}$ ) and $12 \mathrm{~min}$ (Q1: $6 \mathrm{~min}, \mathrm{Q} 3: 22 \mathrm{~min}, \mathrm{E})$ after anesthesia induction. Hypotensive episodes were treated with a mean of $60 \pm 24 \mathrm{mg} \quad(0.79 \pm 0.35 \mathrm{mg} / \mathrm{kg}) \mathrm{C} / \mathrm{T}$

\section{Effectiveness endpoints}

AUC between observed and $S B P_{\min }$ Mean targeted SBP increase (i.e., the difference between $\mathrm{SBP}_{\min }$ and the value measured at diagnosis) was observed to be higher with $\mathrm{C} / \mathrm{T}$ than with $\mathrm{E}$ (• Table 1 and - Fig. 2; diastolic blood pressure is shown in Supplementary Fig. 1). During our analyses it became clear that this observation may impact the first primary endpoint. Box-Cox transformation was performed to normalize right skewed AUC data and no significant differences in normalized AUC values were found between treatment arms (AUC values [formal unit is the product of pressure, pressure, and time: $\left.\mathrm{mm} \mathrm{Hg}^{\star} \mathrm{mm} \mathrm{Hg}^{\star} \mathrm{min}\right]$ : C/T 12.58; E 11.86; estimate [97.5\% CI]: 0.21 [-0.14; 0.55]; $p=0.1827$ ). Despite this, post-hoc analysis showed an overall treatment-related difference between both arms for change in SBP from baseline (estimate [95\% CI]: 2.49 [1.86; 3.12]; $p<0.0001)$. SBP changes were significantly higher with $\mathrm{C} / \mathrm{T}$ from $5 \mathrm{~min}$ onwards when compared with $\mathrm{E}(p<0.02)$. In the first $15 \mathrm{~min}$ after administration, $29.0 \%(n=217)$ of patients in the $\mathrm{C} / \mathrm{T}$ arm exceeded the upper target SBP limit (i.e., $\left.1.3 \times \mathrm{SBP}_{\min }\right)$ vs $28.2 \%(n=211)$ in the $\mathrm{E}$ arm.

\section{New occurrence of heart rate $\geq 100$ beats $/ \mathrm{min}$}

Among the 1496 patients in the PP analysis set 75 (5.0\%) experienced tachycardia. No treatment-related difference in the incidence of new occurrence of tachycardia was observed (estimate [97.5\% CI]: 0.15 $[-0.40 ; 0.69] ; p=0.5432)$. Post-hoc analysis examining change in heart rate from baseline showed an overall treatment-related difference between both arms (estimate [95\% CI]: $-3.07[-3.36 ;-2.77]$; $p<0.0001)$. While heart rate was essentially unchanged in patients receiving $\mathrm{C} / \mathrm{T}$, it was elevated in those treated with $\mathrm{E}$ (• Fig. 3 ). In contrast to the $\mathrm{C} / \mathrm{T}$ arm, a dose-dependent effect on heart rate was shown in the $\mathrm{E}$ arm (Supplementary Fig. 2).

\section{Additional boluses/measures}

Significantly fewer additional boluses (estimate $[95 \% \mathrm{CI}]:-0.20[-0.29 ;-0.11]$; 


\begin{tabular}{|c|c|c|}
\hline Parameter & $\begin{array}{l}C / T \\
(n=749)\end{array}$ & $\begin{array}{l}E \\
(n=747)\end{array}$ \\
\hline \multicolumn{3}{|l|}{ Presumed causes of hypotension, $n(\%)$} \\
\hline Medically induced & $379(50.6)$ & $394(52.7)$ \\
\hline Depth of anesthesia & $254(33.9)$ & $248(33.2)$ \\
\hline Hypovolemia & $49(6.5)$ & $72(9.6)$ \\
\hline $\begin{array}{l}\text { Intraoperative positioning leading to a redistribution of } \\
\text { blood volume }\end{array}$ & $45(6.0)$ & $22(2.9)$ \\
\hline Other reasons & $15(2.0)$ & $6(0.8)$ \\
\hline \multicolumn{3}{|l|}{ Hemodynamic parameters } \\
\hline SBP preoperative $(\mathrm{mm} \mathrm{Hg})$ & $147 \pm 23$ & $146 \pm 22$ \\
\hline DBP preoperative $(\mathrm{mm} \mathrm{Hg})$ & $80 \pm 13$ & $79 \pm 13$ \\
\hline HR preoperative (beats/min) & $73 \pm 13$ & $72 \pm 12$ \\
\hline SBP at time of diagnosis $(\mathrm{mm} \mathrm{Hg})$ & $81 \pm 13$ & $81 \pm 12$ \\
\hline DBP at time of diagnosis $(\mathrm{mm} \mathrm{Hg})$ & $49 \pm 10$ & $49 \pm 9$ \\
\hline MAP at time of diagnosis $(\mathrm{mm} \mathrm{Hg})$ & $60 \pm 10$ & $60 \pm 9$ \\
\hline HR at time of diagnosis (beats/min) & $63 \pm 14$ & $61 \pm 13$ \\
\hline Ratio SBP diagnosis/SBP preoperative & $0.6 \pm 0.1$ & $0.6 \pm 0.1$ \\
\hline Targeted increase in SBP $(\mathrm{mm} \mathrm{Hg})$ & $26 \pm 11$ & $23 \pm 11$ \\
\hline \multicolumn{3}{|c|}{$\begin{array}{l}\text { Data are shown as mean } \pm S D \text { unless stated otherwise } \\
A C E \text { angiotensin-converting-enzyme, } A S A \text { American Society of Anesthesiologists, } A T-2 \text { antago- } \\
\text { nist angiotensin II receptor antagonist, } C / T \text { cafedrine/theodrenaline, } D B P \text { diastolic blood pressure, } \\
E \text { ephedrine, } H R \text { heart rate, } M A P \text { mean arterial pressure, } S B P \text { systolic blood pressure, } S D \text { standard } \\
\text { deviation }\end{array}$} \\
\hline
\end{tabular}

$p<0.0001)$ and additional accompanying measures (estimate [95\% CI]: -0.12 $[-0.20 ;-0.04] ; p<0.0032)$ were applied in patients treated with $\mathrm{C} / \mathrm{T}$ compared with E (• Fig. 4). The most frequently used measures in each treatment arm are shown in $\bullet$ Table 2.

\section{Physician experience and satisfaction with $\mathrm{C} / \mathrm{T}$ vs. $\mathrm{E}$}

The experience of the attending physician with either study drug was comparable $(p=0.4643)$ (Supplementary Table 1). With respect to physician satisfaction, the percentage of anesthetists rating the rapidity of onset as good or very good was higher in the C/T arm (estimate [95\% CI]:5.29 [0.79; 9.78]; $p=0.0214$ ) (Supplementary Table 1$)$. The same was also true concerning treatment precision (estimate [95\% CI]: $7.46[2.52 ; 12.4] ; p=0.0032)$.

\section{Safety}

A total of 118 of 1711 patients (6.9\%) of all patients in the FAS population (C/T: $n=65$ [7.9\%], E: $n=53$ [6.0\%]; inotropic and vasopressor effects, meaning the term inopressor best describes their mechanism of action and differentiates them from other sympathomimetic agents. Inopressors may be particularly suitable for treatment of hypotension occurring in association with propofol use as they counteract both cardiac impairment and vasodilation $[1,6]$.

There is considerable variation in the thresholds used to define IOH [16]. Recent recommendations suggest avoidance of a mean arterial pressure (MAP) of $<55-65 \mathrm{~mm} \mathrm{Hg}$ or a drop of $>40-50 \%$ in SBP [17]. Our definition $(<100 \mathrm{~mm} \mathrm{Hg}$ SBP and/or $>20 \%$ drop in SBP) was therefore considered to be relatively liberal by comparison [12]. As MAP at time of diagnosis was $60 \mathrm{~mm} \mathrm{Hg}$ for $\mathrm{C} / \mathrm{T}$ and $\mathrm{E}$ and the drops in SBP at diagnosis were $45 \%(\mathrm{C} / \mathrm{T})$ and $44 \%(\mathrm{E})$, values obtained in this study align with current recommendations.

As there is no general consensus regarding optimal blood pressure targets, the minimum target $\mathrm{SBP}_{\text {min }}$ was defined here on a case by case basis by the treating physician. Recent studies indicated that individualized blood pressure management may in fact be preferable compared with a more standard strategy using predefined threshold values $[18,19]$. While numerically higher AUC values were observed in patients treated with $\mathrm{C} / \mathrm{T}$, these values were not significantly different between treatment arms; however, when evaluating the AUC data it must be taken into account that these values reflect not only the course of SBP but also the targeted increase in SBP. While SBP values at time of diagnosis were comparable between treatment arms, targeted increase in SBP values were higher in patients treated with $\mathrm{C} / \mathrm{T}$, which complicated interpretation of the results. The reason for this difference is not obvious as the protocol endeavored to appropriately match surgical departments based on predefined criteria [10]. The experience of the attending anesthetist with either study drug was also comparable in both treatment arms. Therefore, one explanation could be that physicians set higher $\mathrm{SBP}_{\min }$ values for patients treated with $\mathrm{C} / \mathrm{T}$ because they anticipate a stronger effect. This assumption is sup- 


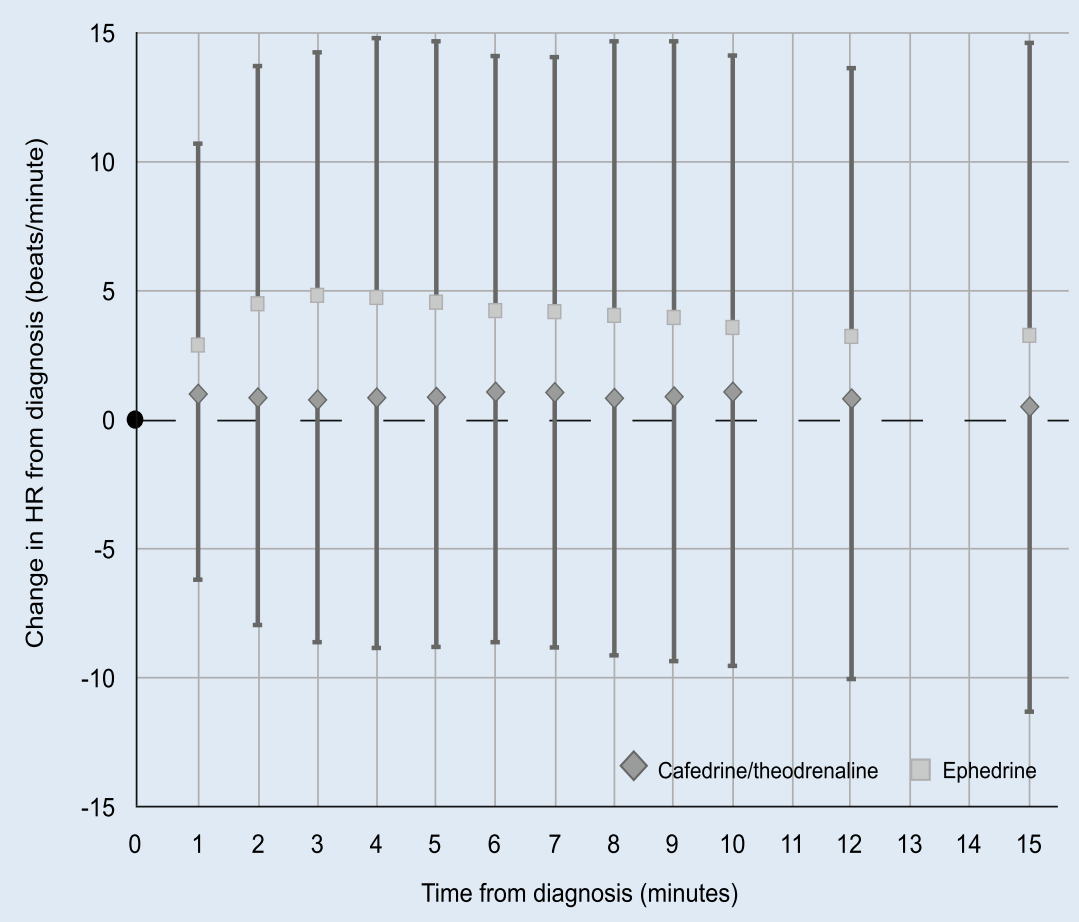

Fig. $3 \Delta$ Change in HR from diagnosis of hypotension observed during the first $15 \mathrm{~min}$ after application of either $\mathrm{C} / \mathrm{T}$ or $\mathrm{E}$. Mean $\mathrm{HR}$ increase from baseline for $\mathrm{C} / \mathrm{T}$ (diamonds) and $\mathrm{E}$ (squares). Error bars show \pm SD. $C / T$ cafedrine/theodrenaline, $E$ ephedrine, $H R$ heart rate, $S D$ standard deviation

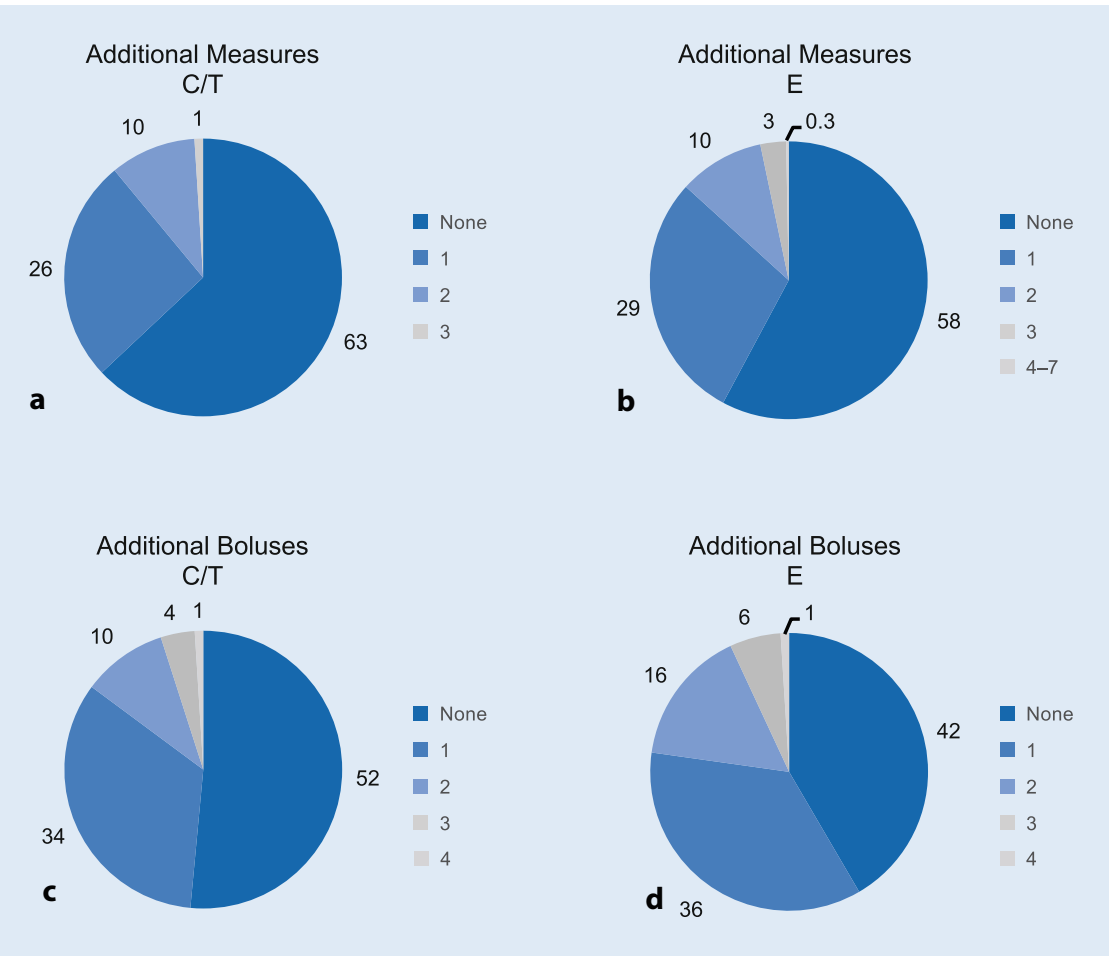

Fig. $4 \Delta$ Percentages of patients receiving other accompanying measures $(\mathbf{a}, \mathbf{b})$ or additional boluses (c, d). C/T cafedrine/theodrenaline, $E$ ephedrine ported by data from the post-hoc analysis showing a pronounced increase in SBP with $\mathrm{C} / \mathrm{T}$.

The incidence of newly occurring tachycardia was not different between treatment arms; however, a treatmentrelated effect was shown in the post-hoc analysis examining change in heart rate from baseline. Heart rate was shown to increase under $\mathrm{E}$, while remaining largely stable with $\mathrm{C} / \mathrm{T}$, which corresponds with other reports in the literature [20, 21]. It should be noted here that beta-blockers were used more frequently in the $\mathrm{E}$ arm, which might have attenuated the effect on heart rate. Future analysis could further examine risk factors that influence the occurrence of tachycardia.

In spite of the increased $\mathrm{SBP}_{\text {min }}$ values and elevated recorded SBP values observed with $\mathrm{C} / \mathrm{T}$, fewer rescue boluses and other accompanying measures were applied to restore hemodynamic stability in the $\mathrm{C} / \mathrm{T}$ arm. One explanation could be that physicians titrate ephedrine more carefully and tend to use accompanying measures more frequently in order to avoid a dose-dependent increase in heart rate, an effect observed in a post hoc analysis. This implies a favorable effect of $\mathrm{C} / \mathrm{T}$, meaning repeated bolus administrations and the need for other timeconsuming measures such as continuous infusion, e.g., using syringe pumps, can be avoided [22]. As the majority of hypotensive states occur during the anesthesia induction period when anesthesiologists are busy preparing for the initiation of surgery, avoidance of additional workload would be advantageous [23, 24].

Evaluation of treatment satisfaction was reported to be better with $\mathrm{C} / \mathrm{T}$. This result is in accordance with the observation that fewer additional interventions were applied in this treatment arm, which might have led to a higher level of satisfaction. As anesthetists in both treatment arms were well-versed in administering each study drug, the observed difference might be attributable to the intrinsic ability of the treatment to stabilize blood pressure. This is in contrast to blinded clinical trials, during which the requirement for additional boluses could be attributable to a subtle underdosing 
$n$ (\%)

All measures

Volume administration/fluid bolus

Decrease in anesthetic depth

Adjustment of positioning for redistribution of volume

Norepinephrine_Infusion

Norepinephrine-Bolus

Other drug treatment

Atropine

Other than atropine

Other measures

$C / T$ cafedrine/theodrenaline, $E$ ephedrine

a Percentage of the total number of patients with accompanying measures in the applicable treatment arm

${ }^{b}$ Percentage of the total number of patients in the applicable treatment arm

C/T

$(n=749)$

Total number

of measures

$360(100)$

$145(40.3)$

$112(31.1)$

$68(18.9)$

$13(3.6)$

$5(1.4)$

$14(3.9)$

7 (1.9)

$7(1.9)$

$3(0.8)$ (non-equivalent doses) of a substance. As equivalent boluses are hard to establish, the magnitude and duration of the effect can be better taken into account in an open label study.

As with any non-interventional study there can be concerns regarding biases or a lack of comparability to controlled clinical study data. As the equivalent doses of $\mathrm{C} / \mathrm{T}$ and $\mathrm{E}$ have not been described in the literature, the study results need to be interpreted with caution. Further research is warranted for a direct comparison with equivalent dose ranges. Norepinephrine or phenylephrine may also constitute promising comparators for future studies. It is open to further debate whether the choice of a specific drug affects clinical outcomes. In addition, it is unclear which regimen and substance achieves hemodynamic stability in the most efficient manner.

\section{Conclusion}

- The effectiveness of cafedrine/ theodrenaline $(\mathrm{C} / \mathrm{T})$ and ephedrine $(\mathrm{E})$ for treatment of intraoperative hypotension was compared in a noninterventional trial.

- While stabilization of blood pressure was shown to be equally manageable with both $\mathrm{C} / \mathrm{T}$ and $\mathrm{E}$, post-hoc analysis examining change in blood pressure from baseline showed that $\mathrm{C} / \mathrm{T}$ produced a more pronounced increase in systolic blood pressure (SBP).

- Heart rate was increased in patients treated with E; however, the overall incidence of tachycardia was comparable between treatment arms.

- Fewer additional boluses and/or other accompanying measures were necessary to restore hemodynamics with $\mathrm{C} / \mathrm{T}$.

- Physicians were overall more satisfied with the rapidity of onset and precision of $\mathrm{C} / \mathrm{T}$ when compared with E.

\section{Corresponding address}

Prof. Dr. L. Eberhart

Department of Anesthesiology \& Intensive

Care, Philipps University Marburg

Baldingerstraße 1, 35033 Marburg, Germany

eberhart@staff.uni-marburg.de

Acknowledgements. The authors thank all hospitals and their study teams participating in the HYPOTENS study. Furthermore, the authors gratefully acknowledge the principal investigator of the HYPOTENS study, L. Eberhart and steering committee members, G. Geldner and P. Kranke. The authors acknowledge the medical writing assistance of Physicians World Europe GmbH, Mannheim, Germany, funded by ratiopharm $\mathrm{GmbH}$ (part of the Teva group). The HYPOTENS study was sponsored by ratiopharm $\mathrm{GmbH}$ (part of Teva).

Members of the HYPOTENS study group. Svenja Albrecht; Christian Asam; Renate Babian; Bernd Bachmann-Mennenga; Markus Barnscheidt; Jannis Bartl; Jan Bartlan; Martina Bauer; Katrin Baumann; Jan-Hinrich Baumert; Karin Becke; Berthold Bein;
E

$(n=747)$

Total number Performed in... of measures patients

$448(100) \quad 314\left(100^{\mathrm{a}} \mid 42.0^{\mathrm{b}}\right)$

$169(37.7) \quad 165\left(52.6^{\mathrm{a}} \mid 22.1^{\mathrm{b}}\right)$

$87(19.4) \quad 86\left(27.4^{a} \mid 11.5^{b}\right)$

$107(23.9) \quad 104\left(33.1^{a} \mid 13.9^{b}\right)$

$51(11.4) \quad 51\left(16.2^{a} \mid 6.8^{b}\right)$

$16(3.6) \quad 12\left(3.8^{a} \mid 1.6^{b}\right)$

$12(2.7) \quad 12\left(3.8^{\mathrm{a}} \mid 1.6^{\mathrm{b}}\right)$

$8(1.8) \quad 8\left(2.5^{\mathrm{a}} \mid 1.1^{\mathrm{b}}\right)$

$4(0.9) \quad 4\left(1.3^{\mathrm{a}} \mid 0.5^{\mathrm{b}}\right)$

$6(1.3)$

$5\left(1.6^{\mathrm{a}} \mid 0.7^{\mathrm{b}}\right)$
Markus Benz; Anca Bergner; Andreas Biedler; Monika Bleise; Jana Bolten; Michael Booke; Felix Brinkmann; Markus Bruckner; Kathrin Brün; Andreas Buchbinder; Eva Bucher; Michael Cercasov; Daniel Chappell; Mark Coburn; Stefan Czarnecki; Fabian Darstein; Thomas Demme; Tristan Diederichs; Anja Diers; Bernd Dohmen; Edith Drop; Cornelie Ebert; Jörg Engel; Susanne Engels-Mühlen; Marco Ensink; Fritz Fiedler; Uwe Fink; Christian Frenkel; Jürgen Friedrich; Michael Fritz; Gebhard Fröba; Andreas Fröhlich; Wolgang Funk; Dafni Galati; Benjamin Gebel; Fabian Geiselbrecht; Wolfgang Geisser; Hans Jürgen Gerbershagen; Christian Gereke; Ali Ghazi; Andre Gottschalk; Claudia Graml; Martin Grapengeter; Clemens-Alexander Greim; Thomas Grote; Joachim Große; Ines Guzman; Bodo Gärten-Schneider; Phillip Hammels; Robert Hanß; Bastian Hauer; Manuela Haupt; Sören Hecht; Antonia Helf; Axel R. Heller; Ria Hennebach; Michael Henrich; Dietrich Henzler; Andreas Hettel; Jan Hirsch; Thilo Hirschberg; Robert Horodko; Christian Höhn; Walter Hölternamm; Michael Höra; Stefan Hübner; Egbert Hüttemann; Franziska Jakob; Holger Janssen; Yvonnne Jelting; Axel Junger; Theresa Just; Sandra Jünger; Gerald Kalmus; Martin Kelbel; Jörg Kieckhäfer; Tobias Kiel; Peter Kienbaum; Marina Kiesel; Mario Kluth; Christian Koch; Lena Korf; Eva Kranke; Alexandra Kratt; Nico Krug; Johannes Kuhn; Ilse Kummer; Oliver Kunitz; Silke Kutz; Sabine Körner; Markus Lange; Mirko Lange; Brita Larsen; Alexander Lay; Robert Liedel; Ulf Lienstedt; Alien Lipka; Martin Lipp; Tim Lohoff; Nico Lorenz; Ina Lotze; Melanie Markmann; Kathrin Meiers; Dirk Meininger; Christian Mey; Ralf Muellenbach; Lukas Müller; Markus Müller; Kerstin MüllerDang; Ahmed Nasralla; Katja Neubieser; Hendrik Nitzsche; Neda Obradovic; Birgit Olberding; Karin Oppenrieder; Christine Oschewski; Wilhelm Alexander Osthaus; Svenja Pabel; Markus Paxian; Thomas Pelchen; Martin Pesch; Margarethe Piontek; Michael Pohl; Niels Peter Preußler; Thorsten Quellenberg; Christoph Radenbach; Benjamin Rehm; Alexander Reich; Anja Reifenstein; Sebastian Reinecke; Anke Ribeaucourt; Monique Richter; Georg Rohe; Adelheid Rosendahl; Rolf Rossaint; Sophie Ruhrmann; Stefan Rußwurm; Kirsten Rämisch; Anabelle Opazo Saez; Michael Sander; Mario Santamaria; Kourosh Savadkouhi; Hermann Schaedel; Annette Schag; Peter Scharmann; Christian Schlegel; Annika Schlemmer; 
Emmanuel Schneck; Axel Schneider; Norbert Schneider; Stephanie Schneider; Norbert Schnobrich; AnnKristin Schubert; Dagmar Schulte; Babett Schwenn; Max Schäfer; Julika Schön; Christian Schütz; Stefan Seyboth; Erdmann Sickmüller; Olaf Simon; Phillip Simon; Rabea Singer; Thomas Standl; Edith Strach; Petra Tepaß; Andreas Thierbach; Claudia Trebes; Nils Ulsamer; Sandro Valle; Benjamin Vojnar; Thomas Volk; Julia van Waesberghe; Jan Wallenborn; Philipp Weber; Henry Weigt; Carola Wempe; Diana Westerheide; Bert Wetzel; Andreas Weyland; Hermann Wrigge; Hinnerk Wulf; Alexander Zarbock; Sebastian Ziemann; Thomas Zinsmeister

Funding. Open Access funding enabled and organized by Projekt DEAL.

\section{Compliance with ethical guidelines}

Conflict of interest. L. Eberhart has received consultant and lecture fees from ratiopharm $\mathrm{GmbH}$ (part of the Teva Group) and supports ongoing research by ratiopharm. G. Geldner and T. Koch have received consulting fees from ratiopharm $\mathrm{GmbH}$ and support ongoing research by ratiopharm. S. Huljic is an employee of ratiopharm GmbH. T. Keller and S. Weber were subcontractors of the contract research organization commissioned by the study sponsor (Mediveritas $\mathrm{GmbH}$, Munich). P. Kranke has received lecturing fees from ratiopharm $\mathrm{GmbH}$ (part of the Teva Group) as well as from Sintetica and supports ongoing research from ratiopharm. All study centers received compensation for each recruited and documented patient $(€ 150$ per case). All remaining authors (A. Kowark, T.-P. Zucker, S. Kreuer and M. Przemeck) declare no other conflicts of interest.

Ethical standards. All procedures performed in studies involving human participants or on human tissue were in accordance with the ethical standards of the institutional and/or national research committee and with the 1975 Helsinki declaration and its later amendments or comparable ethical standards. Informed consent was obtained from all individual participants included in the study. The leading ethics committee at the Philipps University of Marburg granted approval for the study on 15 April 2016 (Az. 14/16).

Open Access. This article is licensed under a Creative Commons Attribution 4.0 International License, which permits use, sharing, adaptation, distribution and reproduction in any medium or format, as long as you give appropriate credit to the original author(s) and the source, provide a link to the Creative Commons licence, and indicate if changes were made. The images or other third party material in this article are included in the article's Creative Commons licence, unless indicated otherwise in a credit line to the material. If material is not included in the article's Creative Commons licence and your intended use is not permitted by statutory regulation or exceeds the permitted use, you will need to obtain permission directly from the copyright holder. To view a copy of this licence, visit http://creativecommons.org/licenses/by/4.0/.

\section{References}

1. Eberhart LH, Bein B (2017) Intraoperative Hypotonie: Therapie. Anasthesiol Intensivmed Notfallmed Schmerzther 52:45-54

2. Overgaard CB, Dzavik V (2008) Inotropes and vasopressors: review of physiology and clinical use in cardiovascular disease. Circulation 118:1047-1056

3. Heller AR, Heger J, Gama De Abreu M et al (2015) Cafedrine/theodrenaline in anaesthesia: influencing factors in restoring arterial blood pressure. Anaesthesist 64:190-196

4. Ratiopharm (2016) Akrinor ${ }^{\circledR}$ prescribing information. https://www.ratiopharm.de/assets/ products/de/label/Akrinor\%C2\%AE\%20200 \%20mg_2\%20ml\%20\%2B\%2010\%20mg_ 2\%20ml\%20lnjektionsl\%C3\%B6sung.pdf? pzn $=10130318$. Accessed 30 Apr 2020

5. Sintetica (2017) Ephedrine meduna prescribing information. https://sintetica.de/wpcontent/uploads/2019/08/FI-Ephedrin-Meduna10mgml-Inj-DE-M\%C3\%A4rz-2017.pdf. Accessed 30 Apr 2020

6. Weitzel M, Hammels P, Schorer Cet al (2018) Hamodynamisches Wirkungsspektrum von Cafedrin/ Theodrenalin bei Anasthesie-assoziierter Hypotension. Anaesthesist 67:766-772

7. Sessler DI, Bloomstone JA, Aronson S et al (2019) Perioperative Quality Initiative consensus statement on intraoperative blood pressure, risk and outcomes for elective surgery. Br J Anaesth 122:563-574

8. Wesselink EM, Kappen TH, Torn HM et al (2018) Intraoperative hypotension and the risk of postoperative adverse outcomes: a systematic review. Br J Anaesth 121:706-721

9. Wu X, Jiang Z, Ying J et al (2017) Optimal blood pressure decreases acute kidney injury after gastrointestinal surgery in elderly hypertensive patients: a randomized study: optimal blood pressure reduces acute kidney injury. J Clin Anesth 43:77-83

10. Ngan Kee WD (2017) The use of vasopressors during spinal anaesthesia for caesarean section. Curr Opin Anaesthesiol 30:319-325

11. Vallee F, Passouant O, Le Gall A et al (2017) Norepinephrine reduces arterial compliance less than phenylephrine when treating general anesthesia-induced arterial hypotension. Acta Anaesthesiol Scand 61:590-600

12. Eberhart L, Geldner G, Huljic S et al (2018) A non-interventional comparative study of the 20:1 combination of cafedrine/theodrenaline versus ephedrine for the treatment of intra-operative arterial hypotension: the 'HYPOTENS' study design and rationale. Curr Med Res Opin 34:953-961

13. Reich DL, Hossain S, Krol Met al (2005) Predictors of hypotension after induction of general anesthesia. Anesth Analg 101:622-628

14. Bijker JB, Van Klei WA, Vergouwe $Y$ et al (2009) Intraoperative hypotension and 1-year mortality after noncardiac surgery. Anesthesiology 111:1217-1226

15. Miller R, Eriksson L, Fleisher L et al (2010) Miller's anesthesia. Churchill Livingstone Elsevier Philadelphia

16. Bijker JB, Van Klei WA, Kappen TH et al (2007) Incidence of intraoperative hypotension as a function of the chosen definition: literature definitions applied to a retrospective cohort using automated data collection. Anesthesiology 107:213-220
17. Rossaint R, Coburn M (2017) Klug entscheiden in der Anasthesie: Ein wichtiger Schritt zur Qualitatsoptimierung. Anaesthesist 66:641-642

18. FrankP, Ilies C, Schmidt Retal (2017) Intraoperative Hypotonie: Bedeutung und Monitoring in der klinischen Praxis. Anasthesiol Intensivmed Notfallmed Schmerzther 52:29-44

19. Futier E, Lefrant JY, Guinot PG et al (2017) Effect of individualized vs standard blood pressure management strategies on postoperative organ dysfunction among high-risk patients undergoing major surgery: a randomized clinical trial. JAMA 318:1346-1357

20. Heller A, Radke J, Koch T (2008) Wirksamkeitsnachweis und Dosis-Wirkungsbeziehungen von Akrinor ${ }^{\circledR}$ bei Patienten unter Allgemeinund Regionalanästhesie. Anasth Intensivmed 49:308-317

21. Sternitzke N, Schieffer H, Rettig G et al (1984) Die Beeinflussung der Herz-Kreislauf-Dynamik durch die Theophyllin-Verbindung Cafedrin und Theodrenalin sowie durch ihre Kombination. Herz Kreislauf 8:401-412

22. Bein B, Christ T, Eberhart LH (2017) Cafedrine/ theodrenaline $(20: 1)$ is an established alternative for the management of arterial hypotension in Germany-a review based on a systematic literature search. Front Pharmacol 8:68

23. Loeb RG (1993) A measure of intraoperative attention to monitor displays. Anesth Analg 76:337-341

24. Weinger MB, Herndon OW, Zornow MH et al (1994) An objective methodology for task analysis and workload assessment in anesthesia providers. Anesthesiology 80:77-92 
Hier steht eine Anzeige.

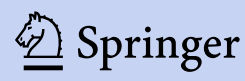

